\title{
Gas Exchange, Biochemical responses and Leaf Water Potential in Seedlings of Seven Tunisian Cork Oak Populations Grown under Water Stress
}

\author{
${ }^{1}$ Ghazghazi Hanene, ${ }^{1}$ Amel Ennajah, ${ }^{1}$ Meriem El aloui,${ }^{2}$ Moufida Westali, \\ ${ }^{1}$ Rania Mechergui, ${ }^{3}$ Bahri Salima, ${ }^{1}$ Mouhamed Nouri, ${ }^{1}$ Abdlawahed Laamouri \\ and ${ }^{1}$ Z. Nasr \\ ${ }^{1}$ Laboratory of Management and Valorisation of Forest Resources, National Research Institute of Rural \\ Engineering, Water and Forestry (INRGREF) \\ ${ }^{2}$ Laboratoire de Biochimie des lipides, Département de Biologie, Faculté des Sciences de Tunis, 2092 El Manar \\ II, Tunisia \\ ${ }^{3}$ Laboratory of Ecology Forest National Research Institute of Rural Engineering, Water and Forestry
} (INRGREF)

\begin{abstract}
Abstact: The climatic changes within the Mediterranean region are known to be responsible of the physionomical variations of the forest ecosystems. This pathology appears under Water stress which undergoes the trees in their natural area, affecting their growth and productivity. The critical roles of osmolyte accumulation under drought stress conditions have been actively researched to understand the tolerance of plants to dehydration. In addition, drought stress-induced generation of active oxygen species is well recognized at the cellular level and is tightly controlled at both the production and consumption levels, through increased antioxidative systems. This review focuses on the ability and strategies of higher plants to respond and adapt to drought stress.The aims of the current work is the study of Quercus suber L. under stress conditions and try to free of eventual physiological and biochimical criterion of evaluation of the tolerance of this species to the water constraint. Efficient conduction of water inside leaves is essential for leaf function, yet the hydraulicmediated impact of drought on gas exchange remains poorly understood. Here we examine the decline of leaf water potential (Yleaf), leaf hydraulic conductance (Kleaf), and Stomatal conductance (gs) in seven Tunisian cork oak populations exposed to controlled drought conditions. During drought the vulnerability of Kleaf to declining Yleaf varied greatly among the species sampled. In conclusion, we noticed that Quercus suber L. show effectively features physiological and biochemical adaptation in drought conditions, with a good behavior to pedoclimatic conditions.
\end{abstract}

Keywords: Quercus suber, water stress, physiological, biochemistry, adaptation.

\section{Introduction}

The comprehensive study of the adaptive mechanisms and responses to water stress for the development of tolerant lines of deciduous trees is becoming increasingly important. The choice of proper rootstocks with tolerance to drought stress is crucial to prevent future problems in the orchard and in order to use water in a more sustainable way. In the Mediterranean area, with an arid or semi-arid climate, water is the principal factor limiting the extension and the intensification of plants. Water resources are increasingly rare; thus saline water is used in agriculture. Global climate change is predicted to dramatically alter precipitation patterns and increase the frequency with which plants will be water stressed (Knapp et al. 2008, Dai 2010). Water stress resistance in woody species can be achieved by avoiding drought or by tolerating it (Levitt, 1980). Quercus suber L. (cork oak) is an evergreen tree from Fagaceae family (Rives et al., 2012a). Due to the unique environmental and climatic conditions, cork oak is grown mainly around the Western Mediterranean area distributed in North Africa (Morocco, Algeria and Tunisia) (Silva et al., 2005), in the south of France and part of Italy as well as in the Atlantic Coast, mainly in Portugal and Spain (Pio et al., 2005). Water deficit caused by drought and osmotic stress effects changes in biochimicals contents, Osmotic adjustment in plants subjected to water deficit may occur through an accumulation of low molecular weight organic solutes. The compatible osmolytes found in higher plants are soluble carbohydrates and proline. The accumulation of soluble carbohydrates in plants has been widely reported as a response to salinity (Ashraf and Harris 2004) and drought (Zhang et al. 2009) in addition to a significant decrease in the net CO2 assimilation rate. Proline, which is widely found in higher plants, accumulates in stressed plants in larger amounts than other amino acids (Ghaderi and Siosemardeh 2011). Proline accumulation is one of the common characteristics in many monocotyledons

DOI: 10.9790/2402-1101020914 $\quad$ www.iosrjournals.org $\quad 9 \mid$ Page


under water deficit. Proline regulates the accumulation of useable nitrogen, is osmotically active and contributes to membrane stability (Bandurska 2000; Bandurska et al. 2010). It may also act as a signaling regulatory molecule able to activate multiple responses that are components of the adaptation process (Maggio et al. 2002). The aim of the present work was to evaluate the physiological and biochemical responses of seven Tunisian cork oak populations submitted to drought stress under controlled conditions. The differences between genotypes and the relationship of the responses with growth induction were evaluated. The interaction between physiological and biochemical parameters was tested to identify drought tolerance markers that could be implemented in peach rootstock breeding programmes for marker-assisted selection. The results of the present study provide sufficient information on cork oak seedlings for reforestation projects.

\section{Materials And Methods}

\section{Plant material}

Cork oak acorns were collected at the end of August and at the beginning of October in from contrasting environments.Over than 700 acorns were collected from the five biggest trees of each one of the seven Quercus suber populations of Kroumirie in the northwest Tunisia and relic populations along the Tunisian dorsal. Studied Cork oak populations were: Mejen essef(MEJ), Feija(FEJ), Ain Snoussie(AS), Sidi Zid(SDZ), Djbel el Serj(JES), Kef el Rand(KER) and Djbel Echaid(JCH).

Table 1. Geographic situation of the seven provenances sampled.

\begin{tabular}{|l|l|l|l|l|}
\hline \multirow{2}{*}{ Site name } & Provenance & \multicolumn{2}{l|}{ Altitude $(\boldsymbol{m})$} & \multicolumn{2}{l|}{ Geographic coordinates } \\
\cline { 3 - 5 } & & & Width & Lenght \\
\hline \multirow{4}{*}{ Kroumirie populations } & MEJ (Mejen essef) & 583 & 36.70 'N & $8.674 \mathrm{E}$ \\
\cline { 2 - 5 } & FEJ (Feija) & 793 & 36.89 'N & $8.774 \mathrm{E}$ \\
\cline { 2 - 5 } & AS (Ain Snoussie) & 571 & $36,81^{\prime} \mathrm{N}$ & $8,91^{\prime} \mathrm{E}$ \\
\hline \multirow{5}{*}{ Relic populations } & SDZ (Sidi Zid) & 933 & 36.47 'N & 10.31 'E \\
\cline { 2 - 5 } & JES (Djbel el Serj) & 709 & $35.924 \mathrm{~N}$ & $9.514 \mathrm{E}$ \\
\cline { 2 - 5 } & KER (Kef el Rand) & 637 & $36.13 \mathrm{~N}$ & $10.1 \mathrm{E}$ \\
\cline { 2 - 5 } & JCH (Djbel Echaid) & 276 & $3623 \mathrm{~N}$ & $9.184 \mathrm{E}$ \\
\hline
\end{tabular}

The acorns were germinated in a greenhouse inside bags of polyethylene (1L) each filled with $1 \mathrm{~kg}$ of a mixture of dry nursery substrate composed of 1/3 clay and 2/3 sand. From the 700 acorns collected, more than 300 have sprouted in optimal weather conditions (without stress). In March, the seedlings were transplanted and grown thereafter in pots $(27 \mathrm{~cm}$ diameter to $30 \mathrm{~cm}$ deep) under non-limiting water conditions. They were placed in a nursery and irrigated regularly until July. Watering was carried out with deionised water to avoid the risk of leaching and loss of nutrients in pots. From July, 140 plants of uniform size were selected and divided into seven blocks of 20 plants each (still in pots).

\section{Measurements of physiological parameters}

Leaf gas exchange measurements were performed with portable photosynthesis systems (Li-6400; Licor Inc., Lincoln, NB, USA). The diurnal changes in CO2 assimilation (A) and stomatal conductance (gs) were recorded after stabilization. Environmental conditions (air temperature T, vapour pressure deficit VPD and photosynthetic photon flux density PPFD) were monitored with the LI-6400 system. Maximal rates of photosynthesis (Amax) and stomatal conductance (gsmax) were determined from daily courses.

\section{Leaf hydraulic conductance $\mathrm{Kf}$}

KF (KF , kg s-1 m-2 MPa-1) (Tyree et al, 1999 ; Nardini, 2001) ou (KF , mmol s-1 m-2 MPa-1) (Sack et Holbrook, 2006), can be define as the rate of water flow through the sheet per unit leaf area divided by the pressure exerted by this flow (Tyree et al, 2005 ; Sack et Holbrook, 2006).

Measurements of leaf hydraulic conductance are realized using the HPFM method (high pressure flow meter) (Sack et al, 2002; Tyree et al, 2005). The technique consists in perfusing degassed water under positive pressure $+\mathrm{P}(\mathrm{MPa})$ in the petiole of a leaf freshly cut from the branch and to mesure the flow at the entry of the petiole. The measured flow values $(\mathrm{F}, \mathrm{mmol} \mathrm{s}-1)$ are automatically recorded in a computer connected to the machine HPFM.

Hydraulic conductivity (KF , mmol s-1 m-2 MPa-1) is calculated as follows where SF is the leaf area in $\mathrm{m}^{2}$ : $\mathrm{KF}=\mathrm{F} /(\mathrm{P} * \mathrm{SF})$

\section{Seedling response to water stress}

Each block for provenance has two sets of 10 plants each, one maintained continuously on the field capacity $(\psi b=-0.3 \pm 0.2 \mathrm{Mpa})$ and the other at a stress level equivalent to $\psi b=-4.5 \pm 0.2 \mathrm{Mpa}$ reached gradually after three weeks of application. Both treatments were randomized within each block. The basic leaf water potentials were determined using a pressure chamber (Albouchi et al. 1997). In this experiment, we tried to apply a level of water deficit approximating to several drought summer conditions in which are our natural cork oaks populations these last years. 
Proline:

Proline content of the leaves was measured according to Bates (Bates, L.S., et al., 1973): Proline was extracted from $0.5 \mathrm{~g}$ of leaf sample by grinding in $10 \mathrm{ml}$ of $3 \%$ sulphosalicylic acid and the mixture was then centrifuged at $10000 \mathrm{~g}$ for $10 \mathrm{~min}$. Two (2) $\mathrm{ml}$ of the supernatant was then added into test tubes to which $2 \mathrm{ml}$ of freshly prepared acid-ninhydrin solution and $2 \mathrm{ml}$ of glacial acetic acid were mixed. The tubes were placed in a water bath for $1 \mathrm{~h}$ at $90^{\circ} \mathrm{Cand}$ the reaction was terminated in ice-bath. The mixture was then extracted with $5 \mathrm{ml}$ toluene and vortexed for $15 \mathrm{sec}$. After allowing standing at least for $20 \mathrm{~min}$ in darkness at room temperature to separate the toluene and aqueous phase, the toluene phase was then carefully collected into test tubes and the absorbance of the fraction was read at $520 \mathrm{~nm}$ with a Shimadzu UV-1700. The proline content in the sample was expressed as $\mu \mathrm{g}-\mathrm{g}$ FW. The standard curve was prepared by employing L-proline.

\section{Total soluble sugars:}

Total soluble sugars content was measured based on the Anthrone method (Irigoyen, J.J., et al., 1992). $0.5 \mathrm{~g}$ of the fresh leaf was crushed in a mortar and $5 \mathrm{ml}$ of $80 \%$ hot alcohol was added to it. The mixture was centrifuged at $9000 \mathrm{~g}$ for $15 \mathrm{~min}(6000 \mathrm{rpm})$. The supernatant obtained was separated into another test tube and $12.5 \mathrm{ml}$ of $80 \%$ alcohol was added to it. $1 \mathrm{ml}$ of the solution was taken and $1 \mathrm{ml}$ of $0.2 \%$ anthrone was added. The mixture was heated in a waterbath at $100^{\circ} \mathrm{C}$ for $10 \mathrm{~min}$. The reaction was terminated by incubating the mixture on ice for $5 \mathrm{~min}$. Total soluble sugars content was determined using a spectrophotometer at $620 \mathrm{~nm}$. Calculation of the total soluble sugars content was done by creating a standard curve using a standard glucose and was expressed in $\mu \mathrm{g} / \mathrm{g}$ freshweight $(\mu \mathrm{g}-\mathrm{g} \mathrm{FW})$.

\section{Statistical analyses}

The measures were the object of an analysis of the variance to two factors (Provenance and water stress), significance levels were established at $\mathrm{P}<0.05$. It was completed by a multiple comparison of the averages by the test of Newman-Keuls test (at 5\%) according. The graphical exits are realized with the software Exel 2000. The differences between populations for the investigated variables were tested with a Principal Component Analysis (PCA). An average value for each trait was calculated. A dispersion and central tendency descriptive analysis was applied to estimate the existing variability.

\section{Results and discussion}

\section{Gas exchange parameters}

Under non-stressed conditions, there were no differences in the water potential of plants provenances. The stress period, leaf water potential was significantly decreased, particularly in sensitive Provenances (figure 1). The effect of drought on leaf water potential was more dramatic in sensitive genotypes AS, SDZ and KER than in resistant genotypes JCH, MEJ and FEJ. In the present study, water stress led to a significant decrease in $\mathrm{K}_{\mathrm{f}}$ and Stomatal conductance $(\mathrm{gs})$; AS presented the highest values of $\mathrm{kf}$ and gs, in contrast with SDZ and kER that presented the lowest values Fig 2 This observation supports the hypothesis that AS more tolerant and SDZ and kER were more sensitive to drought conditions. This stomatal response has also been reported by Nogueira et al. (1998) and Nogueira and Santos (2000). Our results showed that, water stressed plants of A. hypogaea presented the largest reductions in the values of leaf water potential. Although several authors have suggested that the reduction in $\mathrm{Cw}$ due to water shortage should be an indicator of stress adaptation and, consequently, a good morpho-physiological marker for stress tolerance, our data do not support this idea because the genotypes A. duranensis 7988 and A. stenosperma SV2411, which were the more drought-sensitive, showed similar decreases to those observed in A. ipaensis that was the more drought-tolerant (André et al. 2010). These results suggest that AS and SDZ population had the highest energetic cost for osmoregulation through the organic solutes synthesis. The occurance of drought-induced disturbances may also have affected the translocation of organic solutes from shoot to root in drought-sensitive genotypes, resulting in the accumulation of these solutes in the shoot (Larsson 1992). 


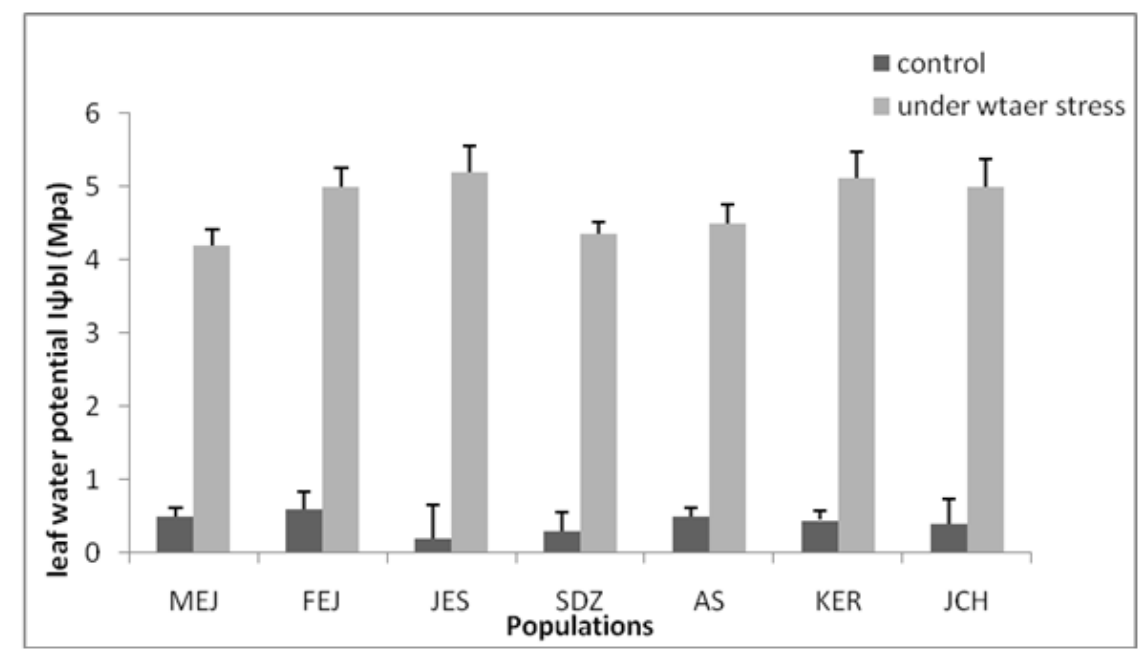

Fig. 1. Leaf water potential (_L) of $Q$. suber under water stress

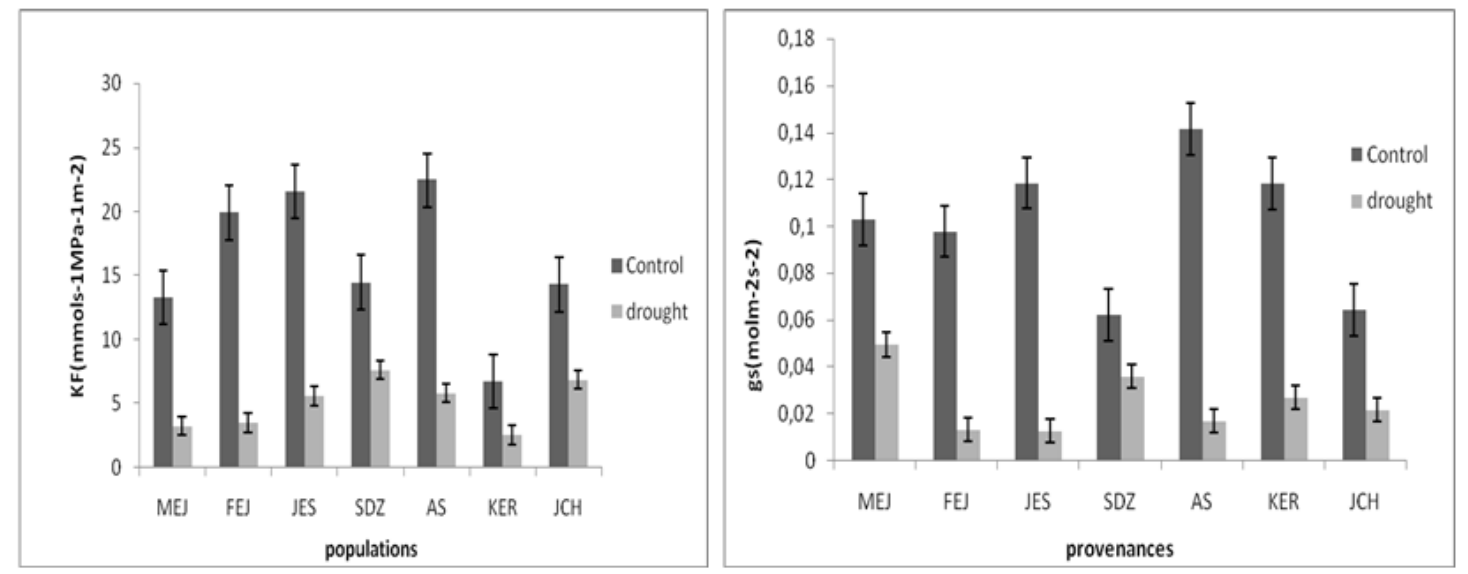

Figure 2. hydraulic conductivity $\left(\mathrm{K}_{\mathrm{f}}\right)$ and stomatal conductance $(\mathrm{gs})$ of seven Tunisian cork oak populations grown under water stress.

\section{Contents of proline and soluble carbohydrates}

Plants respond to drought stress using different physiological and biochemistry strategies. Some osmolytes such as proline and soluble sugars are widespread throughout the plant kingdom. The analysis of variance for proline, soluble sugars is summarized in Table 2; 3 , and it showed significant effects $(\mathrm{P} \leq 0.01)$ of water deficit stress on all the studied traits( table 4). Differences among provenances were significant for the studied traits and the interaction between water treatments and provenances was significant for all the studied traits (Table 4). Water deficit stress increased the levels of proline, soluble sugars (Table 2). Water stress increased the contents of soluble in leaf of all populations studied. In leaves, the highest increases were observed in MEJ and AS and the lowest in JES, FEJ. The stressed roots of KER and SDZ presented a medium increase of $\%$ in the carbohydrates content (table 2). This was in agreement with the results observed in other studies (Xiangwen et. al. 2008). A strong correlation between sugar accumulation and osmotic stress tolerance has been widely reported, including transgenic experiments (Bartels and Sunkar 2005). Sugars have different functions in plants (from energy storage to signaling), and plants utilize several sugar-based strategies to adapt to environmental stresses (chaves et al. 2003).

Proline content also increased as a result of water stress for all populations (table 3). However, this increase was more evident in leaves of MEJ and KER than others. In leaves, the highest increases were observed in MEJ and KER. It is well known that plants under stress may accumulate small molecular mass proteins that could be used as a source of storage nitrogen that could be mobilized after stress relief or removal (Parida and Das 2005). Proline and carbohydrates are the two most important organic solutes that are accumulated in higher plants under drought conditions (Changhai et al. 2010; Sumera and Asghari 2010). It is well known that free proline level increases in response to drought (Rampino et al. 2006). Proline and carbohydrates are the two most important organic solutes that are accumulated in higher plants under drought conditions (Changhai et al. 2010; Sumera and Asghari 2010). It is well known that free proline level increases in response to drought (Rampino et al. 2006). 
Table 2: Effect of water stress treatments on total sugars

\begin{tabular}{|l|l|l|}
\hline \multicolumn{2}{|l|}{ témoins } & Water deficit stress \\
\hline MEJ & $68,73 \pm 0.0021$ & $294,55 \pm 0.014$ \\
\hline FEJ & $72,82 \pm 0.0021$ & $149,80 \pm 0.0049$ \\
\hline JES & $78,61 \pm 0.0014$ & $138,90 \pm 0.0021$ \\
\hline SDZ & $76,57 \pm 0.0127$ & $202,59 \pm 0.0099$ \\
\hline AS & $130,0 \pm 0.0064$ & $297,3 \pm 0.0099$ \\
\hline KER & $101,4 \pm 0.0007$ & $194,07 \pm 0.00035$ \\
\hline JCH & $110,63 \pm 0.0127$ & $267,98 \pm 0.0071$ \\
\hline
\end{tabular}

Table 3: Effect of water stress treatments on proline

\begin{tabular}{|l|l|l|}
\hline & témoins & Water deficit stress \\
\hline MEJ & $0,013 \pm 0.0021$ & $0,18 \pm 0.002$ \\
\hline FEJ & $0,027 \pm 0.0007$ & $0,14 \pm 0.002$ \\
\hline JES & $0,097 \pm 0.0028$ & $0,14 \pm 0.054$ \\
\hline SDZ & $0,033 \pm 0.0014$ & $0,05 \pm 0.014$ \\
\hline AS & $0,103 \pm 0.0021$ & $0,15 \pm 0.008$ \\
\hline KER & $0,0135 \pm 0.0007$ & $0,12 \pm 0.018$ \\
\hline JCH & $0,022 \pm 0.0014$ & $0,13 \pm 0.030$ \\
\hline
\end{tabular}

Table 4: Relationships between some parameters in seedlings of seven Tunisian cork oak populations grown under water stress

\begin{tabular}{|l|l|l|l|l|l|l|}
\hline & tr & proline & sucre & P & kf & gs \\
\hline tr & 1 & $0.78^{*}$ & $0.81^{*}$ & $-0.87^{* * *}$ & $-0.85^{* * *}$ & $-0.87^{* * *}$ \\
\hline proline & $0.78^{*}$ & 1 & $0.74^{*}$ & $-0.58^{*}$ & $-0.54^{*}$ & $-0.58^{*}$ \\
\hline sucre & & & 1 & $-0.66^{*}$ & $-0.67^{*}$ & $-0.62^{*}$ \\
\hline P & & & & 1 & $0.73^{*}$ & $0.78^{*}$ \\
\hline kf & & & & & 1 & $0.82^{*}$ \\
\hline gs & & & & & & \\
\hline
\end{tabular}

Units: traitemnt (tr), proline (pro), sucre (suc), populations (p), leaf hydraulic (Kf), and stomatal conductance (gs); *, $P<0.05 ; * *, P<0.001 ; * * *, P<0.0001$.

Finally, in order to examine if the differentiation is a consequence of genetic drift and/or of natural selection, it has performed a cluster analysis. Dissimilarity of Pearson based on aggregation method was found to separate the provenances into three clusters at a mean distance of 0.35: cluster 1 included MEJ, AS and JCH populations; Cluster 2 with FEJ and JES populations and cluster 3 included the rest of populations (Fig.3). According to the amount of variation of some parameters, populations from AS, were clearly separated from the rest of populations. It was distinguishable by the high $\mathrm{kf}$ and gs parameters. In the end, this analysis allowed us to identify the most fertile populations, most resistant face future climates hardening including AS and JCH populations.

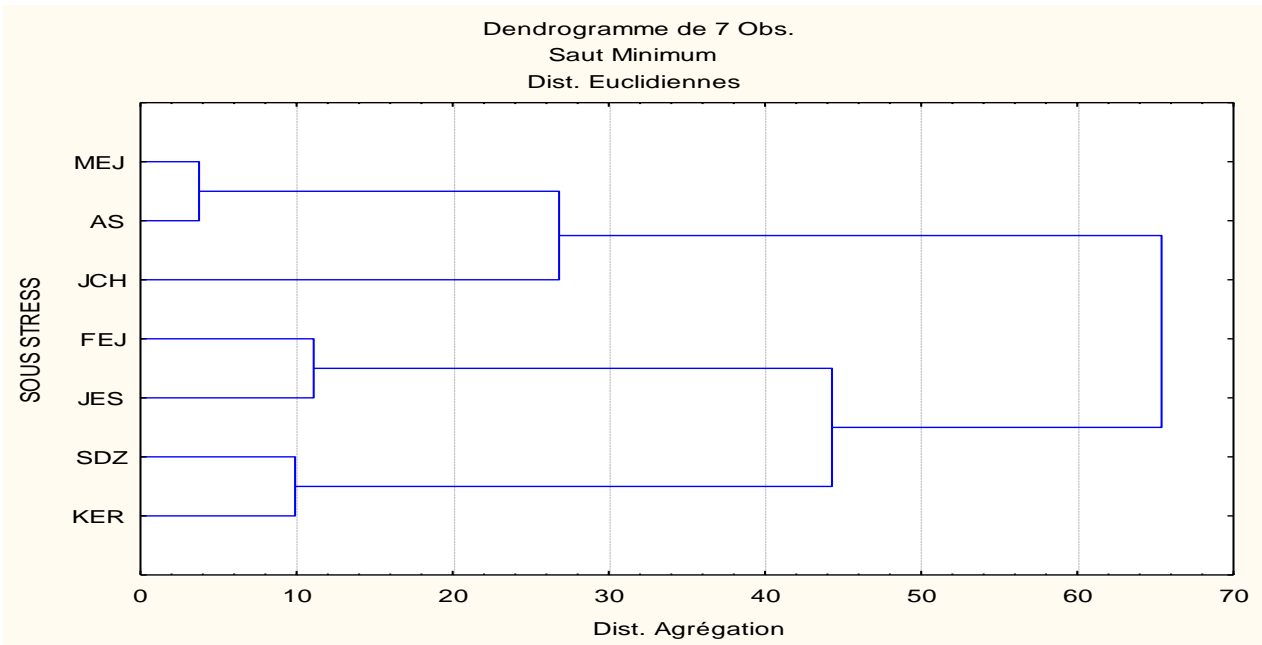

Figure 3 . Dendrogram of Cork oak populations clustered based on Dissimilarity of Person Method (Aggregation). 


\section{Conclusion}

In view of findings of the present study, it can be concluded that water stress strongly affected both physiological and biochemical parameters. A further detailed study is also needed to elucidate the underlying anatomical and processes and genetic parameters which are responsible for differential responses of Quercus Suber Populations.

\section{References}

[1]. Albouchi, R., Ghrir, M.h. El Aouni.,1997. Endurcissement 'a la s'echeresse et accumulation de glucides solubles et d'acides amin'es libres dans les phyllodes d'Acacia cyanophylla Lindl.Anal. Forest. Sci.54 :155-168.

[2]. André, D. Azevedo, Neto, Rejane, J.M.C. Nogueira, Péricles, A., Melo Filho,Roseane C., Santos. 2010. Physiological and biochemical responses of peanut genotypes to water deficit. Journal of Plant Interactions, Vol. 5, No. 1, March 2010, 1_10.

[3]. Ashraf, M., Harris, P.J.C., 2004. Potential biochemical indicators of salinity tolerance in plants. Plant Sci. 166: 3-16

[4]. Bates, L., Waldren, R.P., Teare, I.D., 1973. Rapid determination of free proline for water-stress studies. Plant and Soil, 39, 205-207

[5]. Bartels, D., Sunkar, R., 2005. Drought and salt tolerance in plants. Critical Reviews in Plant Sciences 24: 23-58.

[6]. Bandurska, H., 2000. Does proline accumulated in leaves of water deficit stressed plants confine cell membrane injury? I. Free proline accumulation and membrane injury in drought and osmotically stressed plants. Acta Physiol. Plant. 22: No 4.

[7]. Bandurska, H., Jozwiak, W., 2010. A comparison of the effects of drought on proline accumulation and peroxidases activity in leaves of Festuca rubra L. and Lolium perenne L. Acta Societatis Botanicorum Poloniae, 79: 111-116.

[8]. Barnabas, B., Jager, K., Feher, A., 2008. The effect of drought and heat stress on reproductive processes in cereals. Plant, Cell \& Environment 31: 11-38DaCosta and Huang .

[9]. Chorfi, A., Taibi, K., 2011. Biochemical screening for osmotic adjustment of wheat genotypes under drought stress. Tropicult 29(2):82-87.

[10]. Changhai, S., Baodi, D., Yunzhou, Q., 2010. Physiological regulation of high transpiration efficiency in winter wheat under drought conditions. Plant Soil Eviron 56(7):340-347.

[11]. Dai, A., 2010. Drought under global warming: a review. - Wiley Interdisciplinary Rev. Climate Change 2: $45-65$.

[12]. Chaves, M.M., Maroco, J.P., Pereira, J.S., 2003. Understanding plant responses to drought - from genes to the whole plant. Functional Plant Biology; 30:239-264.

[13]. Cochard, H., Casella, E., Mencuccini, M., 2007. Xylem vulnerability to cavitation varies among poplar and willow clones and correlates with yield. Tree Physiol 27: 1761-.

[14]. Ghaderi, N., Siosemardeh, A., 2011. Response to Drought Stress of Two Strawberry Cultivars (cv. Kurdistan and Selva). Hortic. Environ. Biotech., 52(1): 6-12.

[15]. Knapp, A. K. , 2008. Consequences of more extreme precipitation regimes for terrestrial ecosystems. - Bioscience 58: $811-821$.

[16]. Larsson, M., 1992. Translocation of nitrogen in osmotically stressed wheat seedlings. Plant Cell Environ. 15(4):447_453.

[17]. Levitt, J., 1980. Response of plants to environmental stresses, 2nd Edn., Vol. 2. Academic Press, New York, pp 93-211. Mooney, H.A., B.G. D.

[18]. Maroco, J.P., Pereira, J.S., 2003. Understanding plant responses to drought - from genes to the whole plant. Functional Plant Biology 30: 239-264.

[19]. Maggio, A., Miyazaki, S., Veronese, P., Fujita, T., Ibeas, J.I., Damsz, B., Narasimhan, M.L., Hasegawa, P.M., Joly, R.J., Bressan, R.A., 2002 Does proline accumulation play an active role in stress-induced growth reduction. Plant J 31: 699-712.

[20]. Nardini, A., M.T., Tyree, S., Salleo., 2001. Xylem cavitation in the leaf of Prunus laurocerasus and its impact on leaf hydraulics. Plant Physiol. 125:1700-1709Sack et Holbrook.

[21]. Nogueira, R.J.M.C., Santos, R.C., Bezerra, Neto, E., Santos, V.F. 1998. Comportamento fisioló gico de duas cultivares de amendoim submetidas a diferentes regimes hídricos. Pesq Agrop Bras. 33(12):1963_1969.

[22]. Nogueira, R.J.M.C., Santos, R.C., 2000. Alterac, , ${ }^{\sim}$ es fisiolo' gicas no amendoim submetido ao estresse hi'drico. R Bras Eng Agric Amb. 4(1):41_45.

[23]. Irigoyen, J.J., Emerich, D.W., SanchezDiaz M., 1992 - Water stress induced changes in concentrations of proline and total soluble sugars in nodulated alfalfa (Medicago sativa) plants, Physiol. Plant. 84: 55-60.

[24]. Parida, A.K., Das A.B.,2005. Salt tolerance and salinity effects on plants: A review. Ecotoxic Environ Saf.60(3):324_349.

[25]. Rampino, P., Pataleo, S., Gerardi, C., Mita, G., Perrotta, C., 2006. Drought stress response in wheat: physiological and molecular analysis of resistant and sensitive genotypes. Plant Cell Environ. : - .29: 2143-2153.

[26]. Silva, H. G. de O., Pires, A. J. V., Silva, F. F. da, Veloso, C. M., Carvalho, G. G. P. de, Cezario, A. S., Santos, C. C., 2005. Effects of feeding cocoa meal (Theobroma cacao L.) and palm kernel cake (Elaeis guineensis, Jacq) on milk intake and yield for lactating goats. Rev. Bras. Zootec., 34 (5): 1786-1794.

[27]. Sumera, I., Asghari, B., 2010. Effect of drought and abscisic acid application on the osmotic adjustment of four wheat cultivars. J Chem Soc Pakistan 32(1):13-19.

[28]. Sack, L., Melcher, P.J., Zwieniecki, M.A., Holbrook, N.M., 2002. The hydraulic conductance of the angiosperm leaf lamina: a comparison of three measurement methods. Journal of Experimental Botany 53: 2177-2184.

[29]. Sack, L., Holbrook ,N.M., 2006. Leaf hydraulics. Annu Rev Plant Physiol Plant Mol Biol 57: 361-381

[30]. Tyree, M.T., Salleo, S., Nardini, A., Lo., Gullo, M.A., Mosca, R.,1999. Refilling of embolized vessels in young stems of laurel. Do we need a new paradigm? Plant Physiology 120, 11-21.

[31]. Tyree, M.T., Nardini, A., Salleo, S., Sack, L., El Omari, B., 2005. The dependence of leaf hydraulic conductance on irradiance: any role for stomatal response. Journal of Experimental Botany 56: 737-744

[32]. Tyree, M.T., Nardini, A, Salleo S, Sack L, El Omari B. 2005. The dependence of leaf hydraulic conductance on irradiance during HPFM measurements: any role for stomatal response. Journal of Experimental Botany 56, 737-744.

[33]. Xiao, X., Xu, X. \& Yang, F. 2008. Adaptive responses to progressive drought stress in two Populus cathayana populations. Silva Fennica 42(5): 705-719. 